\title{
Tsunami hazard for the city of Catania, eastern Sicily, Italy, assessed by means of Worst-case Credible Tsunami Scenario Analysis (WCTSA)
}

\author{
R. Tonini, A. Armigliato, G. Pagnoni, F. Zaniboni, and S. Tinti \\ Department of Physics, Sector of Geophysics, University of Bologna, Italy \\ Received: 27 November 2010 - Revised: 16 March 2011 - Accepted: 17 March 2011 - Published: 2 May 2011
}

\begin{abstract}
Eastern Sicily is one of the coastal areas most exposed to earthquakes and tsunamis in Italy. The city of Catania that developed between the eastern base of Etna volcano and the Ionian Sea is, together with the neighbour coastal belt, under the strong menace of tsunamis. This paper addresses the estimation of the tsunami hazard for the city of Catania by using the technique of the Worst-case Credible Tsunami Scenario Analysis (WCTSA) and is focused on a target area including the Catania harbour and the beach called La Plaia where many human activities develop and many important structures are present. The aim of the work is to provide a detailed tsunami hazard analysis, firstly by building scenarios that are proposed on the basis of tectonic considerations and of the largest historical events that hit the city in the past, and then by combining all the information deriving from single scenarios into a unique aggregated scenario that can be viewed as the worst virtual scenario. Scenarios have been calculated by means of numerical simulations on computational grids of different resolutions, passing from $3 \mathrm{~km}$ on a regional scale to $40 \mathrm{~m}$ in the target area. La Plaia beach results to be the area most exposed to tsunami inundation, with inland penetration up to hundreds of meters. The harbour turns out to be more exposed to tsunami waves with low frequencies: in particular, it is found that the major contribution to the hazard in the harbour is due to a tsunami from a remote source, which propagates with much longer periods than tsunamis from local sources. This work has been performed in the framework of the EU-funded project SCHEMA.
\end{abstract}

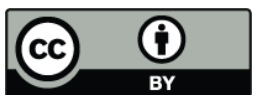

Correspondence to: $\mathrm{R}$. Tonini (roberto.tonini@bo.ingv.it)

\section{Introduction}

Catania lies in the middle of the eastern Sicily coast, one of the most seismic and tsunami-prone areas of the Mediterranean Sea. It has a long and rich history and it is the second largest city in Sicily, with a metropolitan area counting more than 750000 inhabitants. It is a marine town where important economic, social, and tourist activities take place very close to the sea. In particular, the harbour and the tourist beach called La Plaia that extends south of the town are strongly exposed to tsunami hazard. In the past the city was strongly affected by tsunamis. The two most recent documented tsunamis are the ones associated with the 11 January 1693 and the 28 December 1908 earthquakes. The source determination of both these events is still an open issue, because it is not clear whether the tsunamis were generated by the earthquake only or by a landslide or by a combination of both. Nowadays the harbour is protected by a long jetty parallel to the main coast and running NS, and it is hence quite different from the ancient smaller port. To the south of the harbour where La Plaia is found, the coast is sandy and low, while to the north it is rocky and high. A sketch of the seismicity and of the tsunami occurrences in the broad region that is examined to assess the tsunami hazard for the town of Catania can be seen in Fig. 1.

In this work we carry out an analysis of the Catania exposition to tsunamis based on the use of the Worst-case Credible Tsunami Scenario Analysis (WCTSA) that was developed within the framework of the activities of the EU-funded project SCHEMA (http://www.schemaproject.org). This is a quite common approach to tsunami hazard evaluation and it is alternative or complementary to the probabilistic approach (often referred to as Probabilistic Tsunami Hazard Analysis,

Published by Copernicus Publications on behalf of the European Geosciences Union. 
PTHA). A full discussion of which one is better or preferable is out of the scope of this paper. Here we simply stress that PTHA is more demanding in terms of input data and of computational analysis: typically in the PTHA approach one examines all possible potential sources (in practice a very high number, including small to large ones) that are characterised by pre-defined occurrence probability laws, computes the tsunamis and the related inundations in the selected target area for each of the sources, and applies probability theory to compute tsunami inundation probabilities corresponding to different return periods. On the other hand, the WCTSA approach focuses on the largest sources, computing the associated tsunamis and inundations produced in the target area. It therefore involves much less computations, resulting in the worst-case inundation map rather than in a probabilistic inundation map. In other words, PTHA seems more exhaustive and more informative than WCTSA since the former takes into account all the sources and estimates of the expected inundation areas corresponding to any specified return time. Examples of applications of WCTSA for tsunami hazard (Tinti et al., 2005a; Okal and Synolakis, 2008; Lorito et al., 2008) and for tsunami forecasting strategies (Titov et al., 2005), as well as more recently of PTHA (e.g. Tinti et al., 2005b; Geist and Parsons, 2006; Annaka et al., 2007; Power et al., 2007; Grezio et al., 2010), can be found in the literature. However, the data needed to perform PTHA are not always available, and using a PTHA technique in cases of lack of data may be questionable. Indeed, the possibility or convenience to use PTHA depends on the amount of available tsunami data, but mostly on the knowledge of the potential sources, and in particular of how well we are able to characterise them in terms of frequency-magnitude laws and of occurrence probability models. If such laws and models can be inferred and assumed for earthquakes, it is often more difficult to make inferences and assumptions for tsunamigenic earthquakes laws, and extremely difficult for tsunamigenic submarine landslides and for tsunamigenic volcanic eruptions. As a consequence, the PTHA approach is reasonable for target areas that are known to be affected by tsunamis of seismic origin. On the contrary, when there are reasons to believe that even non-seismic tsunamigenic sources can play a role for a given target area, using a WCTSA method is strongly recommendable.

This is the main motivation why the WCTSA technique has been adopted to assess the tsunami hazard for the city of Catania. The WCTSA method can be split into three main steps. The first consists in the identification of a number of credible sources capable of producing the most significant tsunamis in the target area of Catania. In the framework of this study, seven tsunami scenarios have been selected on the basis of tectonic considerations and of the largest historical events affecting the town in the past centuries. Four of them are based on two local events that occurred in 1693 and 1908; the other three are built on a remote source located in the western Hellenic Arc and are based on a tsunami event

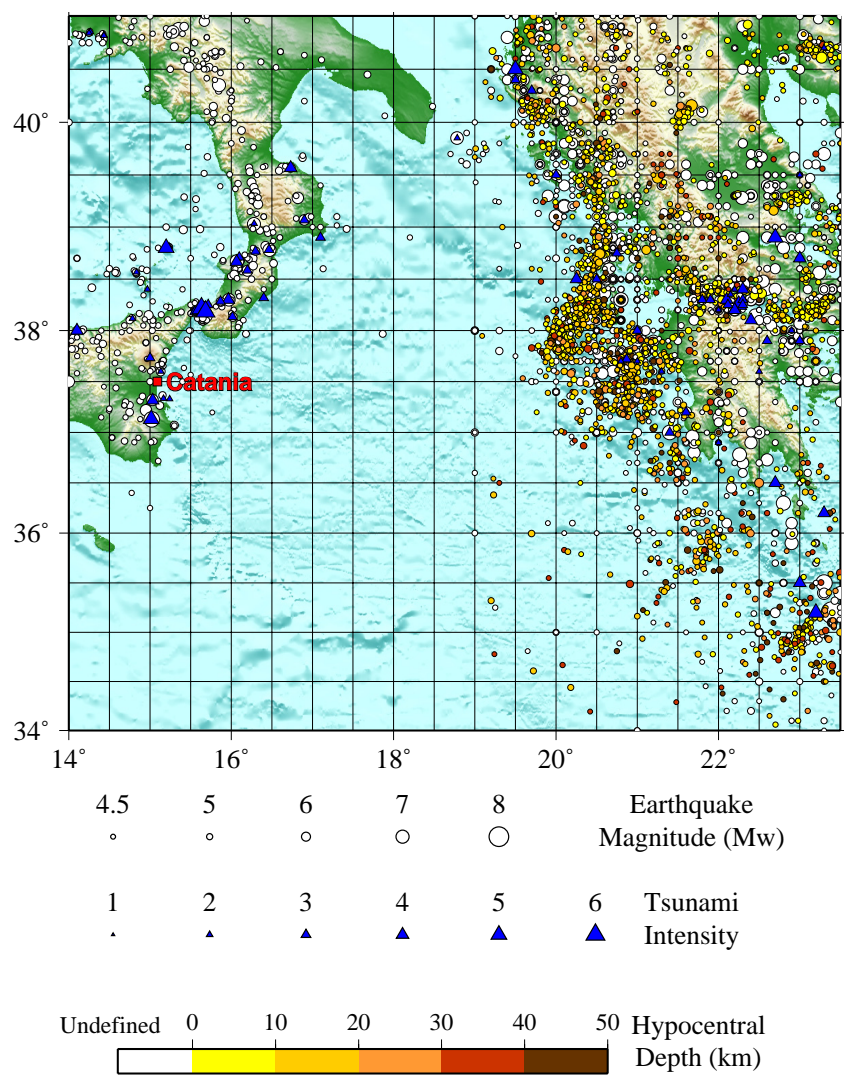

Fig. 1. Sketch of the region of interest. Earthquakes (circles) and tsunami events (triangles) of the Ionian sea are plotted together. Earthquakes are classified for class of magnitude (size of the circle) greater than 4.5 and for hypocentral depth (colour scale). The seismic dataset has been compiled putting together three catalogues (CPTI Working Group, 2004; Papaioannou et al., 2000; Papazachos et al., 2007). Tsunamis and their intensities (size of the triangle) are drawn after Tinti et al. (2001a).

that took place in $365 \mathrm{AD}$. The choice of the sources and of their size, which of course determines the tsunami size, is the result of careful scientific considerations, but has a certain degree of arbitrariness since it comes from subjective analysis. The problem of subjectivity and of the related uncertainties deserves special attention and has been treated in this paper by performing a sensitivity analysis on the source size as will be explained later on. The second step consists of simulating the propagation of the associated tsunamis and computing the inundation in the target area for each of the seven sources. The target area includes the harbour of Catania and the long La Plaia beach, stretching for several kilometres south of the town and populated by many locals and tourists (see red rectangle in Fig. 5). The third and last step is to build a unique aggregated scenario by combining together all of the computed scenarios. Given a specific tsunami physical variable (for instance the wave height), this means selecting for 
Table 1. Magnitude $\left(M_{\mathrm{W}}\right)$ and seismic moment $\left(M_{0}\right)$ for the earthquake scenarios considered. $M_{0}$ has been derived from $M_{\mathrm{W}}$ by means of the Hanks and Kanamori (1979) law. Seismic parameters have been determined using empirical regression curves (Wells and Coppersmith, 1994; Blaser et al., 2010; Strasser et al., 2010), assuming the rigidity parameter $\mu$ equal to $30 \mathrm{GPa}$.

\begin{tabular}{lcc}
\hline Scenario & $M_{\mathrm{W}}$ & $M_{0}(\mathrm{Nm})$ \\
\hline $365 \mathrm{~F} 1$ & 8.3 & $3.16 \times 10^{21}$ \\
$365 \mathrm{~F} 2$ & 8.3 & $3.16 \times 10^{21}$ \\
$365 \mathrm{~F} 3$ & 8.5 & $6.32 \times 10^{21}$ \\
$1693 \mathrm{E}$ & 7.2 & $7.07 \times 10^{19}$ \\
$1908 \mathrm{E}$ & 7.0 & $3.40 \times 10^{19}$ \\
\hline
\end{tabular}

each location the maximum value of that variable calculated for the various individual scenarios. Hence, the final aggregated scenario will represent the strongest expected effect in each location.

\section{Selection of the most tsunamigenic sources}

The choice of the sources is probably the step of the overall study that requires the highest attention, because it can strongly affect the final results of the analysis. Detailed inundation maps must be representative of credible scenarios if they have to be used for helping local authorities in the frame of mitigation or emergency plans for handling tsunamis. Here seven cases are presented, based on historical events and, when possible, on available observations. Three of them are remote sources based on the $365 \mathrm{AD}$ event that occurred offshore Crete, Greece (named hereafter 365 F1, 365 F2, 365 F3). The remaining four sources are based on two disastrous local events that occurred in the East of Sicily and in the Messina Straits in 1693 and in 1908. Since the direct cause of these two historical tsunamis is still uncertain, though there is no doubt on the occurrence of the earthquakes, two different source hypotheses have been made for both the 1693 (named $1693 \mathrm{E}$ and $1693 \mathrm{~L}$ ) and the 1908 (named $1908 \mathrm{E}$ and 1908 EL) events. The assumptions made on the source parameters will be described and justified in the next subsections. The vertical co-seismic displacement fields of the seismic sources (365 F1, 365 F2, 365 F3, 1693 E, 1908 E, and 1908 EL) are shown in Figs. 2 and 3, together with the initial body extension of the landslide source (1693 L). Table 1 lists the values of the moment magnitude $\left(M_{\mathrm{W}}\right)$ and of the seismic moment $\left(M_{0}\right)$ that we adopted for the tsunamigenic earthquakes selected to build the scenarios.

\subsection{The 365 AD event}

Three remote source hypotheses have been considered as potentially tsunamigenic for Catania. They are based on the very strong earthquake with estimated magnitude $M_{\mathrm{W}}=8.3$
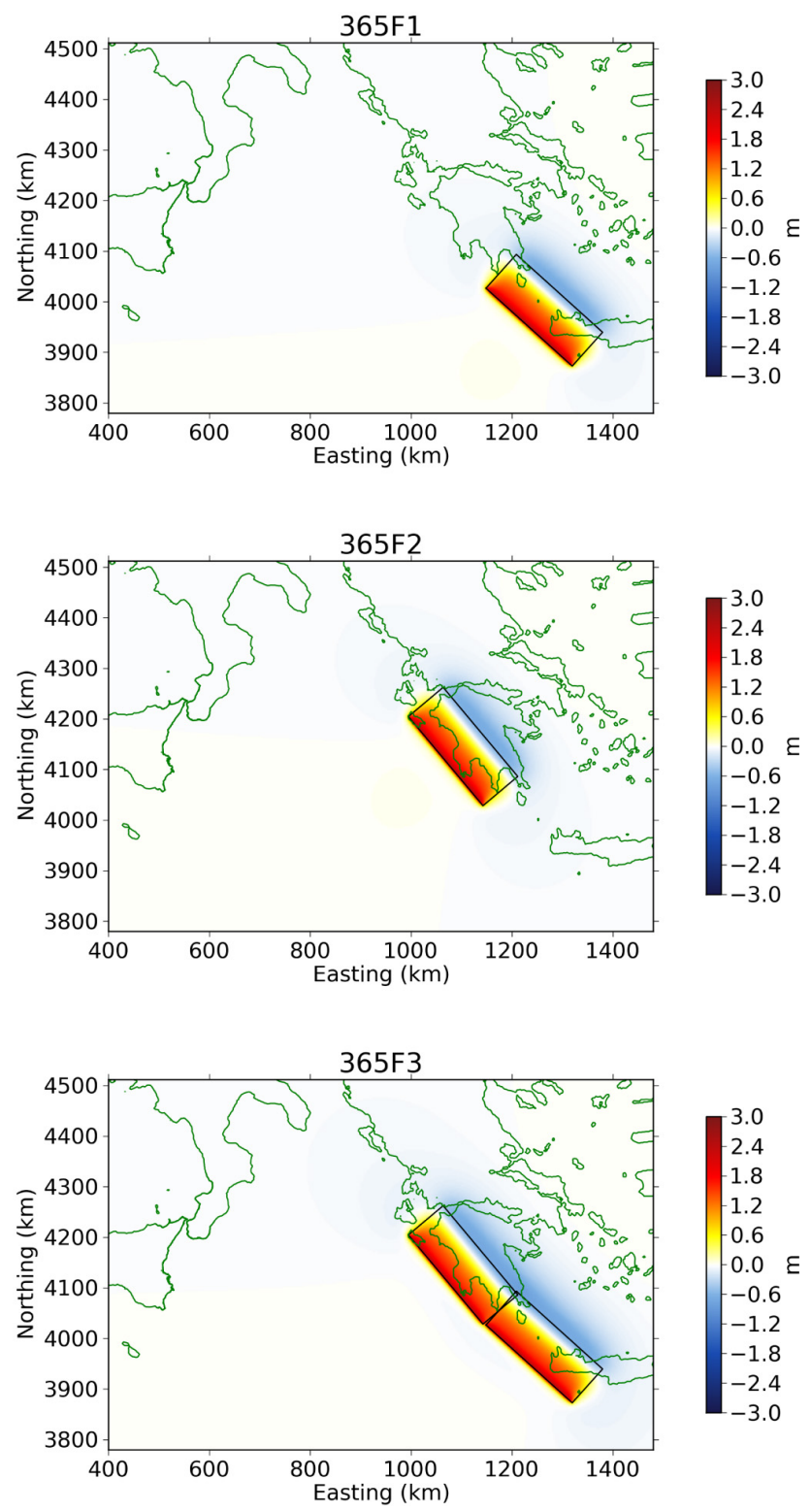

Fig. 2. Initial condition for the three source model hypotheses based on the $365 \mathrm{AD}$ earthquake. The initial conditions correspond to the co-seismic vertical displacement of the sea-floor.

that occurred on the 21 July 365 AD in the western Hellenic Arc (HA), Greece (Papazachos, 1996). The hypocenter of this earthquake was probably located off western Crete, along a major thrust fault parallel to the western Hellenic trench. This quake represents the best documented event capable to trigger a tsunami with a destructive potential very far from the source in the Mediterranean Sea. The tsunami that followed was very huge and inundated many coastal sites in Greece, Africa, and southern Italy (Stiros, 2001; Guidoboni and Comastri, 2005; Shaw et al., 2008). This event has been identified as the largest credible earthquake with the highest 
Table 2. Seismic parameters for the tsunamigenic earthquake sources used to characterise the 365 AD scenarios. Subfaults F1 and F2 correspond to the fault hypotheses $365 \mathrm{~F} 1$ (the southern segment) and 365 F2 (the northern segment) in Fig. 2. The 365 F3 scenario corresponds to the sum of both segments.

\begin{tabular}{lrr}
\hline & F1 & F2 \\
\hline Length $(\mathrm{km})$ & 230 & 230 \\
Width $(\mathrm{km})$ & 90 & 90 \\
Strike $\left(^{\circ}\right)$ & 312 & 320 \\
Dip $\left(^{\circ}\right)$ & 21 & 21 \\
Rake $\left(^{\circ}\right)$ & 90 & 90 \\
Slip $(\mathrm{m})$ & 5 & 5 \\
Upper Edge Depth $(\mathrm{km})$ & 5 & 5 \\
\hline
\end{tabular}

tsunamigenic potential for the Hellenic Arc area and was already used in the frame of tsunami scenario studies applied to the Mediterranean Sea (Tinti et al., 2005a; Lorito et al., 2008). In this work we consider three different scenarios. The first one (365 F1) is based on recent works about the reconstruction of the 365 event causative fault (e.g. Shaw et al., 2008). The second one (365 F2) is a possible future rupture involving the trench section of the HA between Crete and Peloponnese, and has been chosen because it could have higher effects on the Catania target area. The third scenario (365 F3) involves both F1 and F2, thus representing the almost complete rupture of the western HA. A simplified model of the faults is illustrated in Fig. 2. The co-seismic slip is assumed to be uniform over the fault plane and the corresponding focal parameters are listed in Table 2.

\subsection{The 1693 event}

A strong seismic sequence starting on 9 January 1693 hit eastern Sicily. The main shock of 11 January was estimated to have magnitude $M_{\mathrm{W}}=7.4$ (CPTI Working Group, 2004) and was followed by a strong tsunami. This earthquake, with maximum macroseismic intensities of X to XI, caused 60000 casualties, 12000 of which in Catania. Historical information about the tsunami is not as substantial as information concerning the earthquake, but it allows deducing some relevant features of the impacting waves. In particular, a negative polarity of the first wave was observed along the entire eastern Sicily coast, and the portion between Catania and Augusta was the one hit by the largest waves (Baratta, 1901; Tinti and Maramai, 1996; Tinti et al., 2004). The identification of the fault plane that was responsible for the 11 January shock is a very difficult task and it is still an open issue. In order to cope with this basic uncertainty, two different source hypotheses have been considered to elaborate tsunami scenarios: the case of an earthquake and the case of a landslide.

Assuming that the tsunami was caused by an earthquake poses the problem of searching for a tsunamigenic fault. Tsunami observations suggest to reject several source hy-
Table 3. Seismic parameters for the tsunamigenic earthquake source 1693 E proposed by Argnani and Bonazzi (2005). S1 and S4 are the extreme segments from north to south.

\begin{tabular}{lrrrr}
\hline & S1 & S2 & S3 & S4 \\
\hline Length $(\mathrm{km})$ & 14.665 & 8.760 & 5.000 & 19.190 \\
Width $(\mathrm{km})$ & 16.500 & 16.500 & 16.500 & 16.500 \\
Strike $\left({ }^{\circ}\right)$ & 329 & 322 & 343 & 360 \\
Dip $\left(^{\circ}\right)$ & 35 & 35 & 35 & 35 \\
Rake $\left(^{\circ}\right)$ & 270 & 270 & 270 & 270 \\
Slip (m) & 3.0 & 3.0 & 3.0 & 3.0 \\
Upper Edge Depth $(\mathrm{km})$ & 0.5 & 0.5 & 0.5 & 0.5 \\
\hline
\end{tabular}

potheses proposed in the literature on the basis of earthquake data that only locate the source inland, and tsunami modelling confirms that the source should be located offshore (Tinti et al., 2001b). Among all the offshore earthquake sources that can be found in the literature (e.g., Bianca et al., 1999; Sirovich and Pettenati, 1999; Monaco and Tortorici, 2000; Gutscher et al., 2006), the most likely rupture area seems to be located along the Hyblaean-Malta escarpment since it provides the best fit with tsunami observations in terms of first wave polarity and wave amplitude (Tinti and Armigliato, 2003). The worst credible scenario considered here is based on the fault described in Argnani and Bonazzi (2005): in our analysis, it is modelled as a set of four subfault segments with focal parameters listed in Table 3.

Because recent offshore bathymetric surveys mapped a number of possible landslide bodies along the HyblaeanMalta escarpment, the possibility of a tsunami induced by a landslide cannot be ruled out. Under this hypothesis, the sources of the 1693 earthquake and tsunami are distinct, and there is no need to reconcile seismic and tsunami observations to a unique cause. Therefore, one possibility is that a non-tsunamigenic earthquake occurring inland (which fits well macrosesimic data) triggered a landslide offshore that in turn caused a tsunami. The tsunamigenic source we take into account in this study is a slide body that was identified during the multi-channel seismic survey MESC2001 carried out by CNR (National Council of Research), described in Argnani and Bonazzi (2005), and that was proved to possess a relevant tsunamigenic potential (Armigliato et al., 2007). The slide was recognised to be of a roto-translational type with modest horizontal displacement that took place in waters deeper than $1800 \mathrm{~m}$ close to the foot of the escarpment about $30-35 \mathrm{~km}$ off Augusta. The main characteristics of the sliding body and of the sliding process are given in Table 4 .

\subsection{The 1908 event}

On the 28 December 1908 a strong earthquake of estimated $M_{\mathrm{W}}=7.2$ (CPTI Working Group, 2004) occurred in the Messina Straits, immediately followed by a tsunami. 
Table 4. Landslide parameters for the tsunami source $1693 \mathrm{~L}$.

\begin{tabular}{lr}
\hline Slide Volume $\left(\mathrm{km}^{3}\right)$ & 4.81 \\
Slide Mass $\left(10^{9} \mathrm{~kg}\right)$ & 12.8 \\
Maximum Thickness (m) & 250 \\
Minimum Depth of the Scar (m) & 1850 \\
Max Run-out Distance (m) & 200 \\
\hline
\end{tabular}

The towns of Messina and Reggio Calabria were severely damaged by the effects of the shock and of the tsunami. Several tsunami observations were reported by eyewitnesses along all the eastern coast of Sicily and the south-western coast of Calabria. Indeed this is the historical tsunami in Italy with the most abundant set of collected data, comparable, in quantity and quality, with data sets of very recent tsunami cases. A lot of run-up data were collected by the field surveys carried out in the weeks following the tsunami, with waves up to $3 \mathrm{~m}$ in Catania and an inundation line that extends to $700 \mathrm{~m}$ at La Plaia beach (Platania, 1909a,b; Baratta, 1910; Tinti and Maramai, 1996; Tinti et al., 2004). A number of tide gauges located at La Valletta harbour (Malta), Ischia (Italy), Naples (Italy), and Civitavecchia (Rome, Italy) recorded the tsunami signal (Tinti and Giuliani, 1983; Gerardi et al., 2008), even though the recorded signals were very weak.

Despite the great efforts in a century of investigations, the identification of the source that triggered the strong 1908 tsunami is still far from being clearly understood. Many seismic source hypotheses have been made by researchers, but no one yet has been able to fully explain the tsunami observations associated with the event (Pino et al., 2009). The uncertainty in the source type is addressed in this study by building two scenarios based on two different sources: the first is a fault characterised by substantially heterogeneous slip and the second is a composite source formed by the previous one and by an additional contribution due to a tsunami source extension to the south.

The seismic source model has been obtained by parameterizing the source hypothesis proposed in a recent work by Valensise et al. (2008). Their work is based on geomorphological and seismotectonic evidences and on the geodetic deformation measured shortly before and after the earthquake by Loperfido (1909). The model is composed of 12 sub-faults with uniform slip in each of them in order to obtain a heterogeneous co-seismic slip distribution over the total fault. Parameters are given in Table 5. The main effect on the sea-floor is a relevant subsidence affecting the whole Messina Straits, but mainly concentrated in the southern part where the Straits is wider and opens to the Ionian sea. This seismic source, like all the reasonable seismic sources proposed for the 1908 event, gives rise to a tsunami that is significantly smaller than the observed one.
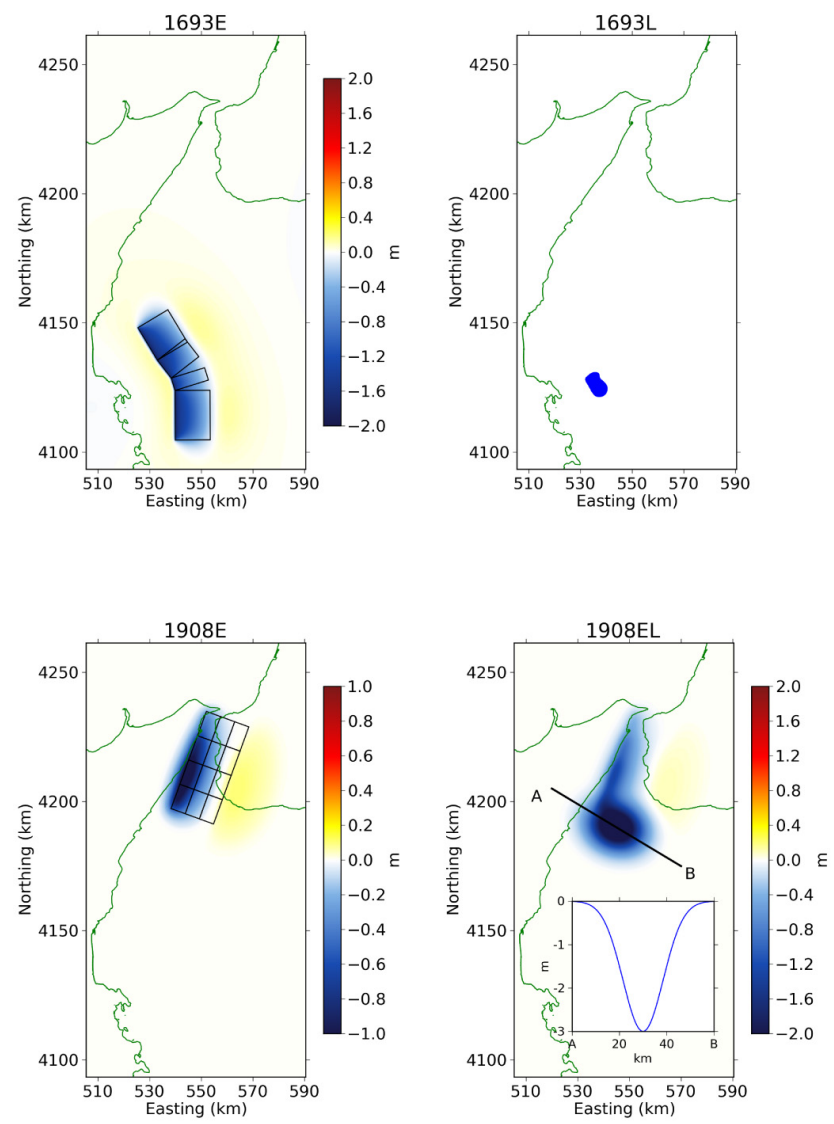

Fig. 3. Initial condition for the source model hypotheses based on the 1693 and 1908 events. For all cases it corresponds to the coseismic vertical displacement of the sea-floor, except for the $1693 \mathrm{~L}$ case where the initial landslide body is plotted.

Very recently it was proposed that the tsunami was caused by a very large submarine landslide (Billi et al., 2008), but geological and geophysical evidences disagree with this hypothesis (Argnani et al., 2009). Nevertheless, the hypothesis of a composite source (e.g. earthquake and landslide) seems more reasonable (Favalli et al., 2009). Hence, the second source taken here combines the contribution of the earthquake source considered before and of an additional source associable to a submarine slide. Since the identification of the responsible slide is still far from the solution, but there is consensus on the need for an additional contributor to the tsunami, we have considered here not a slide but an equivalent static source capable of producing a tsunami more compatible with the historical observations made on the coasts of Sicily. More specifically, an elliptically shaped Gaussianlike depression in the southern part of the fault has been added to the initial sea surface displacement caused by the 12 sub-fault system. This additional source has been identified capable of producing a sea water withdrawal as the first tsunami arrival on the coast and it can be roughly considered as due to an "equivalent landslide" source. It is relevant 
Table 5. Seismic parameters for the tsunamigenic earthquake source based on the one proposed by Valensise et al. (2008). S1 to S4 are the westernmost rectangles from south to north in Fig. 3. The same convention is followed for the central ones (S5 to S8) and the easternmost ones (S9 to S12). UED stands for Upper Edge Depth.

\begin{tabular}{|c|c|c|c|c|c|c|c|c|c|c|c|c|}
\hline & S1 & S2 & $\mathrm{S} 3$ & $\mathrm{~S} 4$ & S5 & S6 & S7 & S8 & S9 & S10 & S11 & $\mathrm{S} 12$ \\
\hline Length (km) & 10.00 & 10.00 & 10.00 & 10.00 & 10.00 & 10.00 & 10.00 & 10.00 & 10.00 & 10.00 & 10.00 & 10.00 \\
\hline Width (km) & 6.67 & 6.67 & 6.67 & 6.67 & 6.67 & 6.67 & 6.67 & 6.67 & 6.67 & 6.67 & 6.67 & 6.67 \\
\hline Strike $\left(^{\circ}\right)$ & 20 & 20 & 20 & 20 & 20 & 20 & 20 & 20 & 20 & 20 & 20 & 20 \\
\hline $\operatorname{Dip}\left(^{\circ}\right)$ & 29 & 29 & 29 & 29 & 29 & 29 & 29 & 29 & 29 & 29 & 29 & 29 \\
\hline Rake $\left(^{\circ}\right)$ & 270 & 270 & 270 & 270 & 270 & 270 & 270 & 270 & 270 & 270 & 270 & 270 \\
\hline Slip (m) & 2.50 & 3.00 & 2.04 & 1.00 & 1.50 & 2.00 & 1.50 & 0.50 & 1.00 & 1.00 & 0.50 & 0.50 \\
\hline UED (km) & 3.00 & 3.00 & 3.00 & 3.00 & 6.20 & 6.20 & 6.20 & 6.20 & 9.50 & 9.50 & 9.50 & 9.50 \\
\hline
\end{tabular}
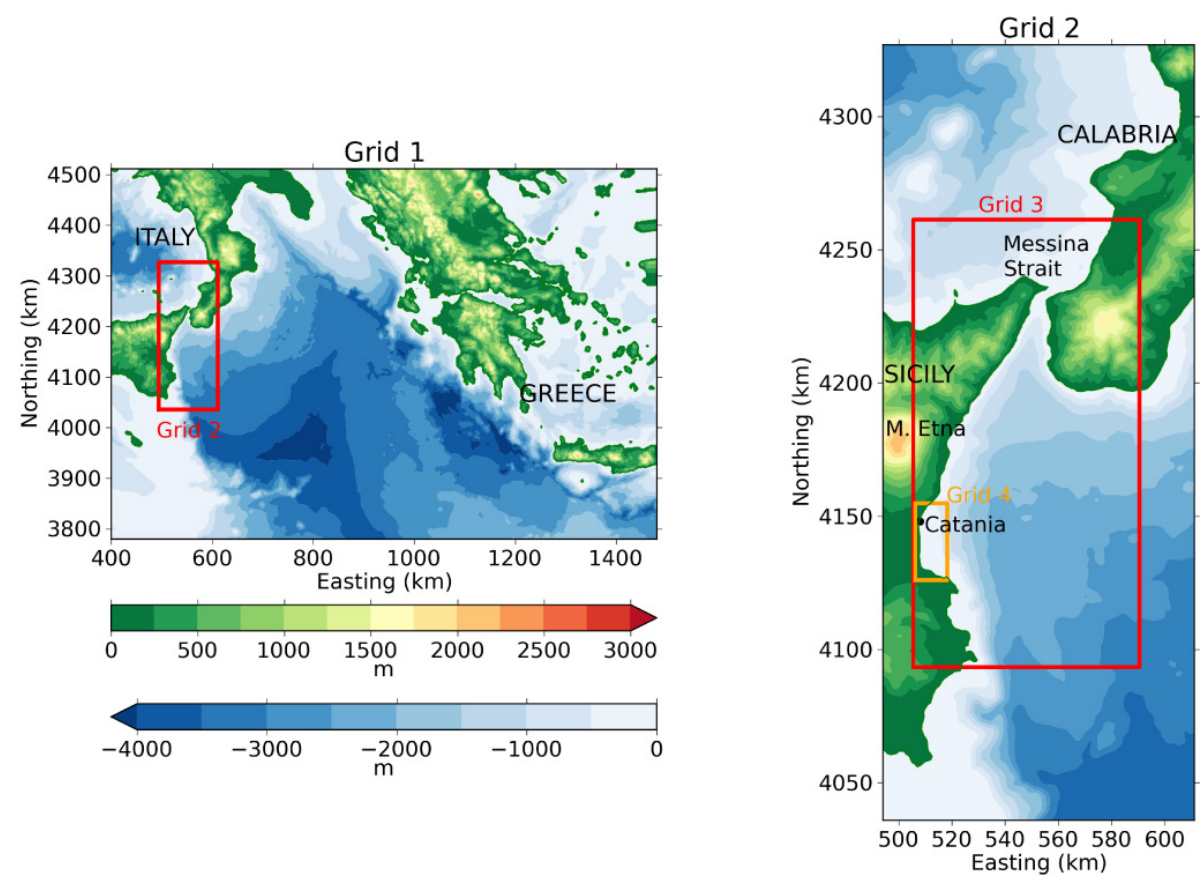

Fig. 4. Geometry and nesting of the computational grids (grid 1 to grid 4) used to perform the tsunami simulations. The grid resolutions are: $3 \mathrm{~km}$ in grid $1,1 \mathrm{~km}$ in grid 2, $200 \mathrm{~m}$ in grid 3, and $40 \mathrm{~m}$ in grid 4.

to point out that historical accounts testify that in most localities of Sicily and Calabria the first tsunami polarity was negative, i.e. sea water was seen first to recede from the shore (Tinti and Giuliani, 1983). The overall initial displacement, together with a section along the $\mathrm{AB}$ axis of the depression, is given in Fig. 3. Orientation and amplitude of the depression have been calibrated against the known tsunami observations along the coast of Sicily and mainly in vicinity of the source.

\section{Numerical modelling}

Tsunamis are long waves and are usually modelled through Navier-Stokes hydrodynamic equations in approximation of shallow water, being their wavelengths much longer than the depth of the water on which they propagate. The numerical model we used to perform tsunami simulations is the code UBO-TSUFD that solves the nonlinear shallow water equations through a finite difference numerical scheme. Equations are calculated on a set of nested regularly-spaced grids with different space resolutions providing more detailed results in selected target areas. Inundation maps are calculated by means of a moving boundary algorithm that dynamically changes the coastline position, depending on the instantaneous wave heights computed at each time step in the wet grid points confining with the dry points. The code has been benchmarked and used in the framework of the two FP6 EU-funded projects TRANSFER (http://www.transferproject.eu) and SCHEMA (http://www. schemaproject.org). For a recent application of the code see 
the paper by Tonini et al. (2011) on the 2009 Samoa tsunami and tsunami forecasting strategies. The code UBO-TSUFD can perform tsunami simulations induced by both seismic and landslide tsunami and it needs to be used coupled to other specific tools which calculate the tsunami initial conditions. For all the seismic sources the initial condition coincides with the vertical sea-floor displacement calculated by means of the classical set of equations for a rectangular fault buried in an elastic half space (Okada, 1992).

The landslide motion has been calculated by means of the code UBO-BLOCK2 that treats the slide as a 2-D matrix of blocks mutually interacting and conserving their volumes, though being free to deform, and computes the slide evolution by means of a Lagrangian model. The code was originally conceived for a one-dimensional landslide evolution (Tinti et al., 1997) and lately adapted to a 2-D geometry (Tinti et al., 2006). Both UBO-TSUFD and UBO-BLOCK2 are in-house codes developed and maintained by the Tsunami Research Team of the University of Bologna.

Landslides-induced tsunami propagation cannot always be well described by the non-dispersive shallow water theory, because slides may involve shorter wavelengths than tsunamis caused by earthquakes and often the use of Boussinesq-type dispersive equations could be more suited. But since the effect of dispersion is to decrease the nondispersive wave amplitude calculated through the shallow water approximation distributing the energy over a longer train of waves, hence the amplitude values resulting from non-dispersive models can be taken as an overestimation of the actual values and can be accepted in the spirit of worstcase scenario approach.

Computations have been performed under the hypothesis of no tidal oscillations, since the tides in the Mediterranean are known to be weak and in the range of some tens of centimetres (e.g., APAT, 2006), apart from very specific cases (see the northern Adriatic) that do not regard eastern Sicily and the area of interest.

\section{Available datasets and computational grids}

Topo-bathymetric details strongly affect the wave evolution close to the coast, leading to the obvious consequence that results achieved by numerical simulations are strongly dependent on the quality of the datasets used to build the computational grids. A good description of the real coastal morphology is absolutely necessary in order to have credible inundation scenarios. Often datasets must be collected by different sources or providers, with the consequence of a lot of extra work in order to match them and to make them consistent, especially in the near-shore areas, where details are more important. The datasets used for this study are listed in Table 6. All topographic and bathymetric data, though available in different coordinate systems, have been integrated into a unique Cartesian reference frame, and, more specifically,

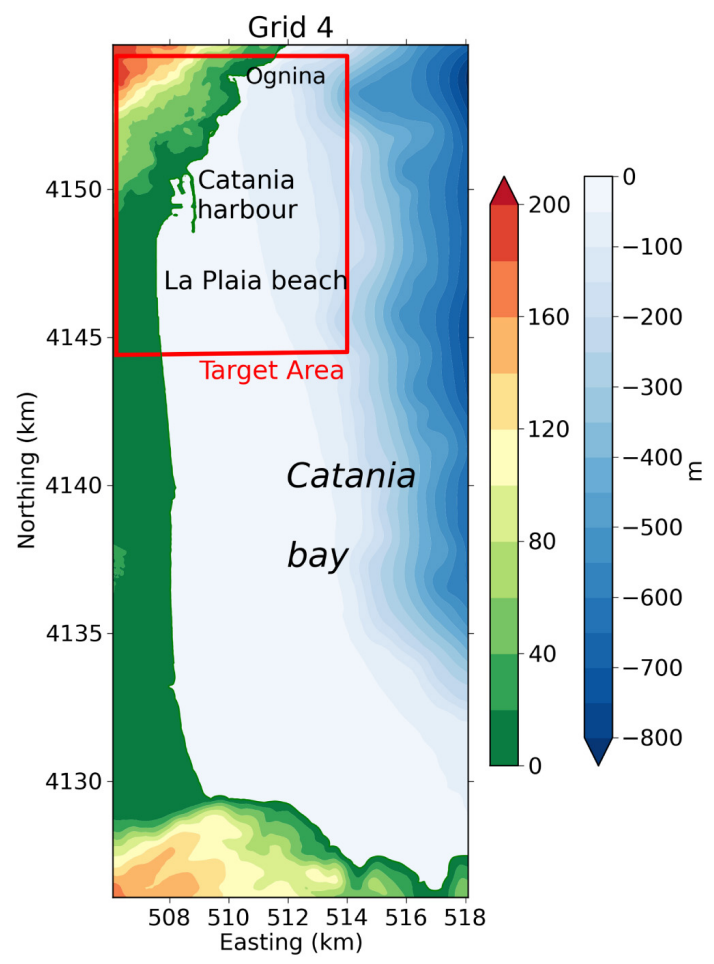

Fig. 5. Topography and bathymetry of grid 4 . The red rectangle shows the target area selected to perform the tsunami hazard analysis for Catania.

into the coordinates of the UTM zone of the city of Catania (33N-WGS84). The geographical areas outside this zone have been treated as an extension of the $33 \mathrm{~N}$ zone, in order to guarantee continuity of the coordinates system throughout the whole region of interest. Through suitable in-house interpolation procedures that were developed specifically for this purpose, a set of four regularly-spaced nested grids with different resolutions has been built. The geographic coverage and the grid scheme are shown in Figs. 4 and 5. Because of the necessity to fully include the sources in the computational domain to simulate tsunami propagation, all four grids have been used to calculate the $365 \mathrm{AD}$ scenarios with generation in the western HA. The grid resolution passes from $3 \mathrm{~km}$ for the regional grid (grid 1) to $40 \mathrm{~m}$ for the smallest grid (grid 4) covering the area around Catania and its bay through two more intermediate grids $(1 \mathrm{~km}$ and $200 \mathrm{~m}$ cell size, respectively for grid 2 and grid 3). The remaining scenarios need two grids only, namely grids 3 and 4 . It is worth pointing out that features smaller than $40 \mathrm{~m}$ would risk to go lost since they might not be captured by the finest grid. However, in cases where removing a feature was believed to conspicuously affect tsunami propagation, the feature was adapted to the grid space step. For instance, obstacles like breakwaters or jetties in the harbour whose width is much smaller than the grid 4 step and whose deletion from the computational grid 
Table 6. Synthetic list of the topo-bathymetric datasets.

\begin{tabular}{lrrrr}
\hline Name & Type* $^{*}$ & Domain & Coordinates & Resolution \\
\hline GEBCO $^{1}$ & BT & Mediterranean & Geographic & 1 arc min \\
SRTM $^{2}$ & $\mathrm{~T}$ & Eastern Sicily & Geographic & $90 \mathrm{~m}$ \\
DRPC-CT $^{3}$ & $\mathrm{~T}$ & Catania district & Cartesian (Gauss-Boaga) & $1: 10000$ \\
ISMAR-CNR $^{4}$ & $\mathrm{~B}$ & Ionian & Geographic & isolines \\
IIM $^{5}$ & $\mathrm{~B}$ & Catania district & Cartesian & $1: 100000,1: 30000,1: 10000$ \\
\hline
\end{tabular}

${ }^{1}$ GEneral Bathymetric Chart of the Oceans. ${ }^{2}$ NASA Shuttle Radar Topographic Mission. ${ }^{3}$ Dipartimento Regionale Protezione Civile di CaTania. ${ }^{4}$ Istituto di Scienze MARine CNR. ${ }^{5}$ Istituto Idrografico della Marina. * B=Bathymetry, T=Topography.

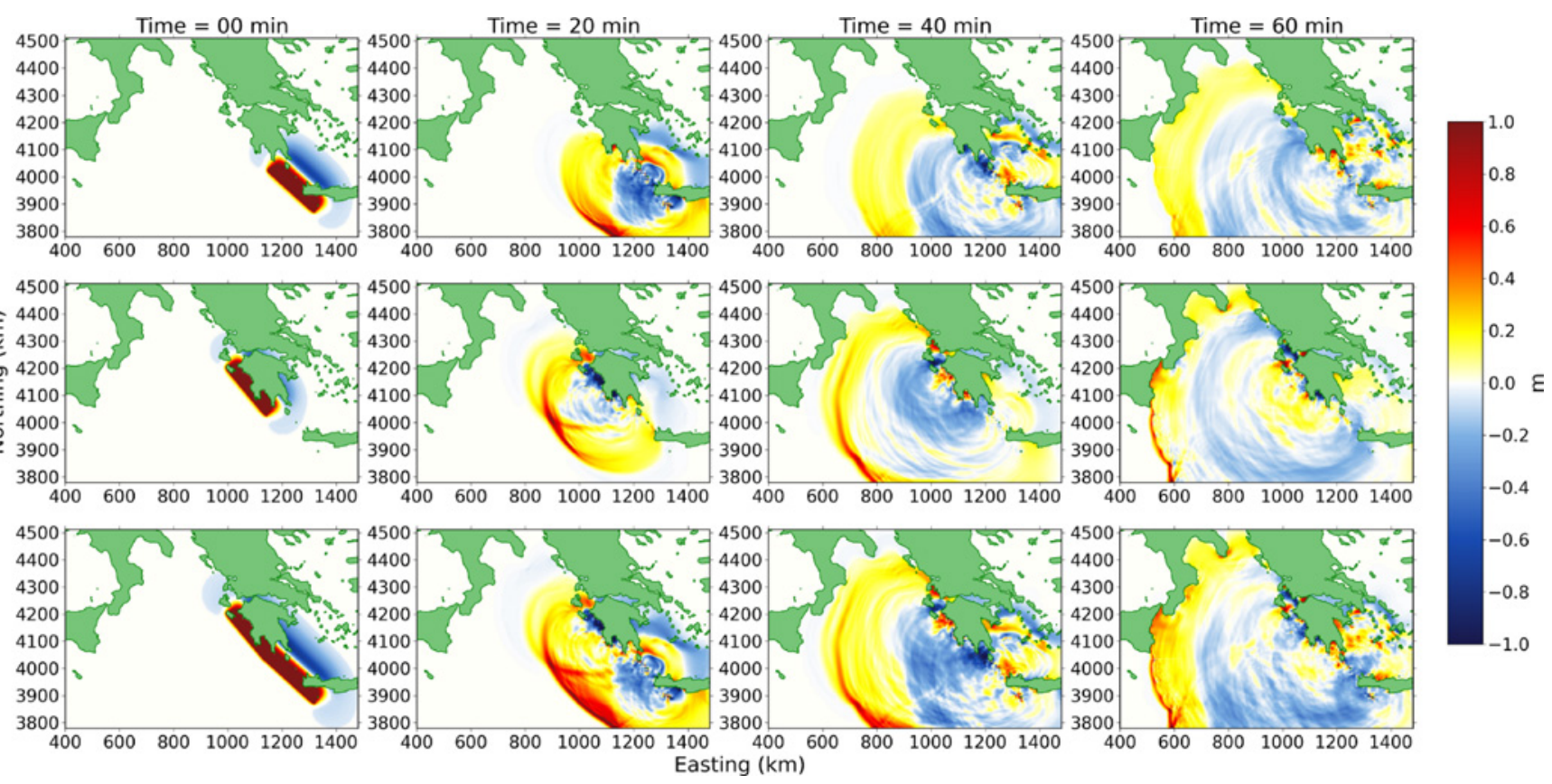

Fig. 6. Tsunami propagation snapshots for 365 F1 (upper panels), 365 F2 (middle panels), and 365 F3 (bottom panels) scenarios.

would significantly affect the tsunami impact are represented as a series of discrete contiguous cells, and therefore have minimum width of $40 \mathrm{~m}$. The target area for this study is the one included in the red rectangle of Fig. 5 and is only a small portion of grid 4 that covers the vaster bay of Catania.

\section{Results of tsunami propagation and inundation modelling}

The second step of the tsunami scenario analysis is the computation of the tsunamis associated with the selected sources.

\subsection{The 365 AD event}

The tsunami following the $365 \mathrm{AD}$ earthquake affected not only the local Greek coasts facing the Ionian Sea, but was able to also reach many locations placed very far from the seismic source, such as Algeria, Egypt and Italy (Guidoboni and Comastri, 2005). Figure 6 shows some significant propagation snapshots for the three scenarios. Even though the African coasts are not included in the computational domain, it is clear that all the coasts of the mid-south Mediterranean basin are significantly exposed to this event. Propagation times are very similar for all the scenarios (the 365 F1 is slightly slower because it is the farthest one) but the leading wave height is appreciably stronger for the 365 F2 and the 365 F3 scenarios, since the northern fault segment is much more effective than the southern one in directing tsunami energy towards eastern Sicily. For all three scenarios, the wave front that moves towards Italy is weaker than the one that moves SW, but still significant for $365 \mathrm{~F} 2$ and for 365 F3 since waves are almost $0.5 \mathrm{~m}$ amplitude offshore. The fields of the maximum sea surface elevation plotted in Fig. 7 (left column) confirm that most tsunami energy 

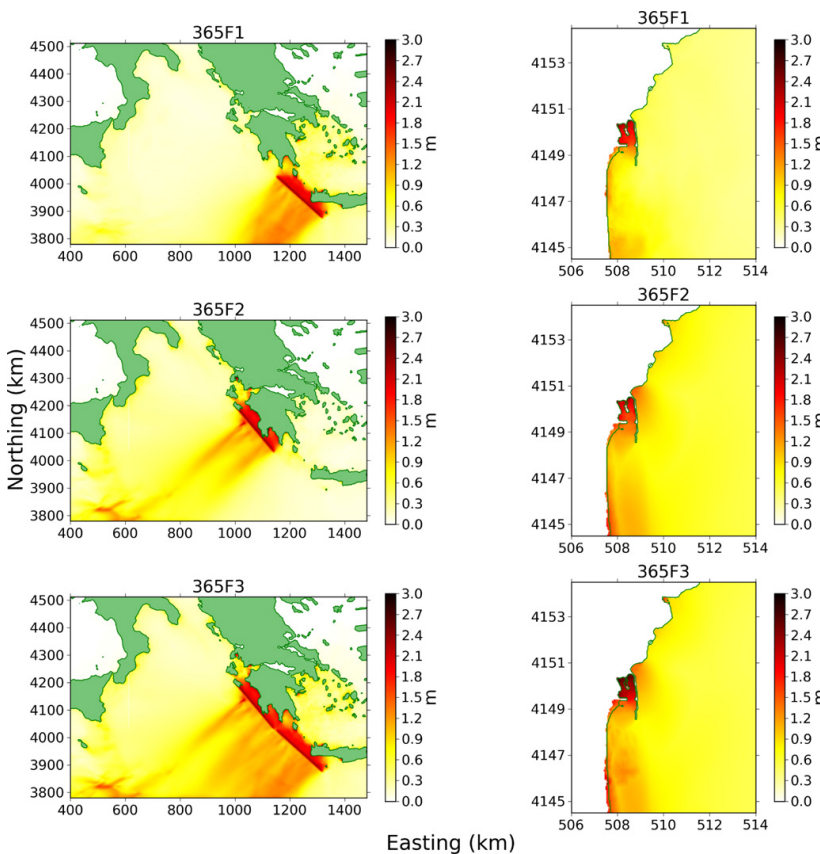

Fig. 7. Maximum water elevation for the three 365 F1, 365 F2 and $365 \mathrm{~F} 3$ scenarios (left column) and their corresponding detailed maximum inundation in Catania (right column).

is distributed close to the source and along the paths that move perpendicular to the fault segments. The largest run-up heights in the target area (Fig. 7, zoomed figures in the right column) reach $3 \mathrm{~m}$ in the inner part of the harbour and some flat and low areas of La Plaia, south of the harbour, are inundated up to a distance of about $200 \mathrm{~m}$ from the shore. On the other hand, the coast north of the harbour is high and tsunami waves cannot significantly penetrate inland. The long breakwater in front of the harbour reflects waves coming from the east with front almost aligned with the coast, decreasing the destructive potential of the attack, but part of the energy is able to penetrate through the southern entrance, submerging some areas inside the harbour, especially in the outer basin.

\subsection{The 1693 event}

The tsunami of the $1693 \mathrm{E}$ case reaches the areas closest to the source in only $3 \mathrm{~min}$ and it takes between 6 and $9 \mathrm{~min}$ to attack the central part of the Ionian Sicily coast and the southern coast of Calabria (Fig. 8, upper panels). The leading front is soon negative with the trough having a length (measured perpendicularly to the front line) decreasing from $20 \mathrm{~km}$ to about $2 \mathrm{~km}$ on approaching the coast of Catania, a case of wavelength shortening that is quite known and that is due to the monotonous dependence of tsunami phase velocity upon sea depth. The tsunami energy pattern is shown in Fig. 9, from which it is clear that the highest run-ups are attained in the coastal zone in front of the source. Offshore,

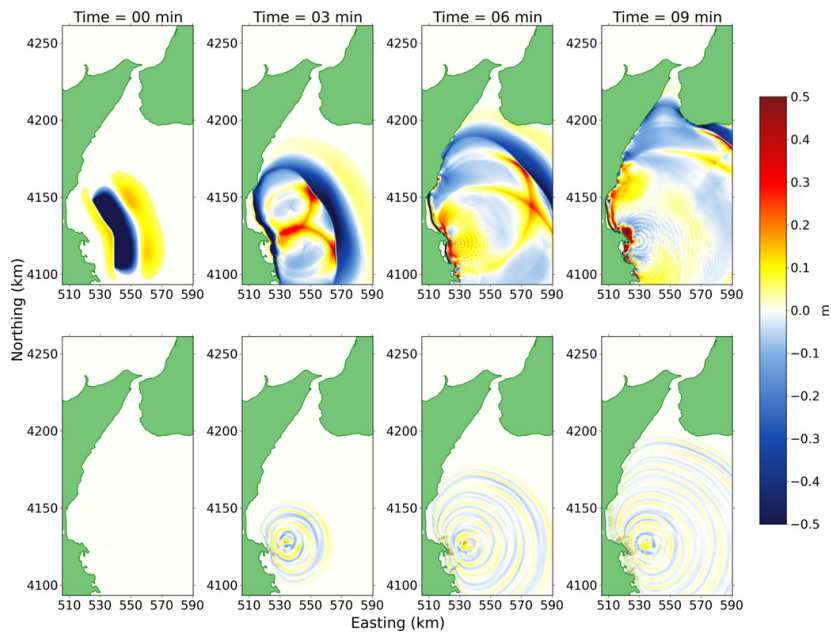

Fig. 8. Tsunami propagation snapshots for 1693 E (upper panels) and $1693 \mathrm{~L}$ (bottom panels) scenarios.
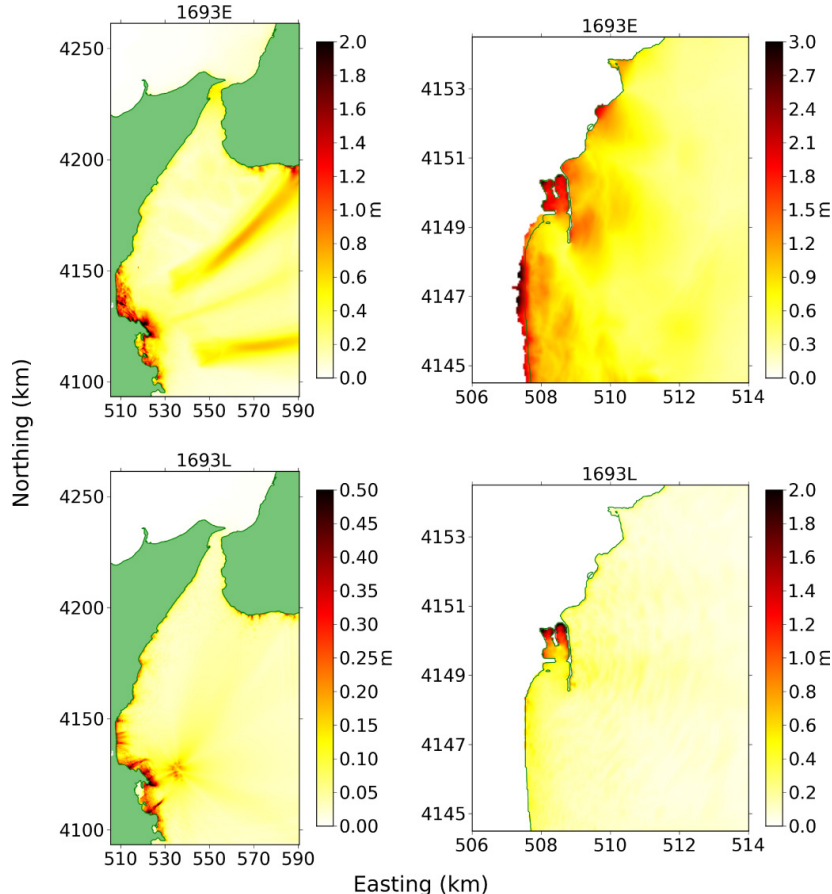

Fig. 9. Maximum water elevation for $1693 \mathrm{E}$ and $1693 \mathrm{~L}$ scenarios (left column) and their corresponding detailed maximum inundation in Catania (right column).

the energy splits in two main beams with opposite bending as the result of bathymetry-induced refraction: the northern one heading NNE towards Calabria coasts and the other going east. The tsunami produced by this source is weak and causes a very limited inundation at La Plaia beach (1-2 m 


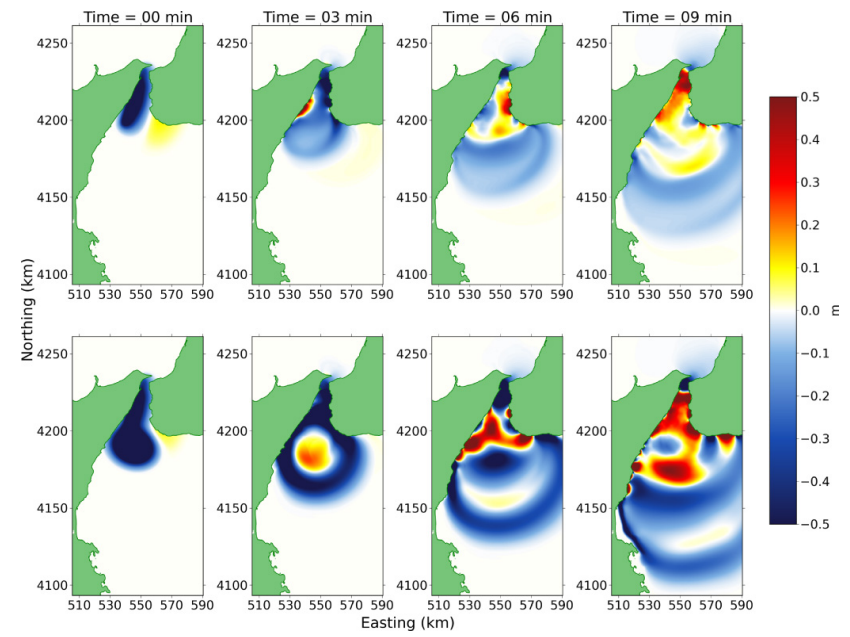

Fig. 10. Tsunami propagation snapshots for 1908 E (upper panels) and 1908 EL (bottom panels) scenarios.

of run-up heights), while the maximum elevations of the sea surface are observed within the inner harbour, where heights over $2 \mathrm{~m}$ can be found (Fig. 9). This means that the tsunami waves tend to be amplified within this basin.

The $1693 \mathrm{~L}$ case produces an alternative scenario for this tsunami event, where the source is a submarine landslide. The tsunami propagates with a radial pattern from the source with almost circular fronts (Fig. 8, lower panels), which is quite typical of sources of limited areal extension. Unlike the earthquake-induced tsunami, the propagation shows a predominance of short waves. The tsunami attacks the bay of Catania with a train of waves arriving parallel to the coast, interacting with the harbour, and forming a quite complicated interference pattern. Maximum sea surface elevations are low in the region and are low even in Catania (Fig. 9), where tsunami has some effects only inside the inner part of the harbour, with the largest elevations ranging from 1 to about $2 \mathrm{~m}$.

It is worth remarking that both source hypotheses $1693 \mathrm{E}$ and $1693 \mathrm{~L}$ give rise to a tsunami that is too weak to reproduce the tsunami observations in the city of Catania (Baratta, 1901; Tinti and Maramai, 1996). This is mainly due to the fact that today's harbour configuration is much different from the late seventeenth-century structure, which coincided more or less with the small inner western basin. The harbour now is much larger and the long NS breakwater is effective in reducing the impact of the attacking tsunamis.

\subsection{The 1908 event}

The tsunami generated by the earthquake source model $1908 \mathrm{E}$ results to be rather weak and inconsistent with the quite numerous observations confirming a large inundation and strong damages caused in Catania (Tinti and Giuliani,

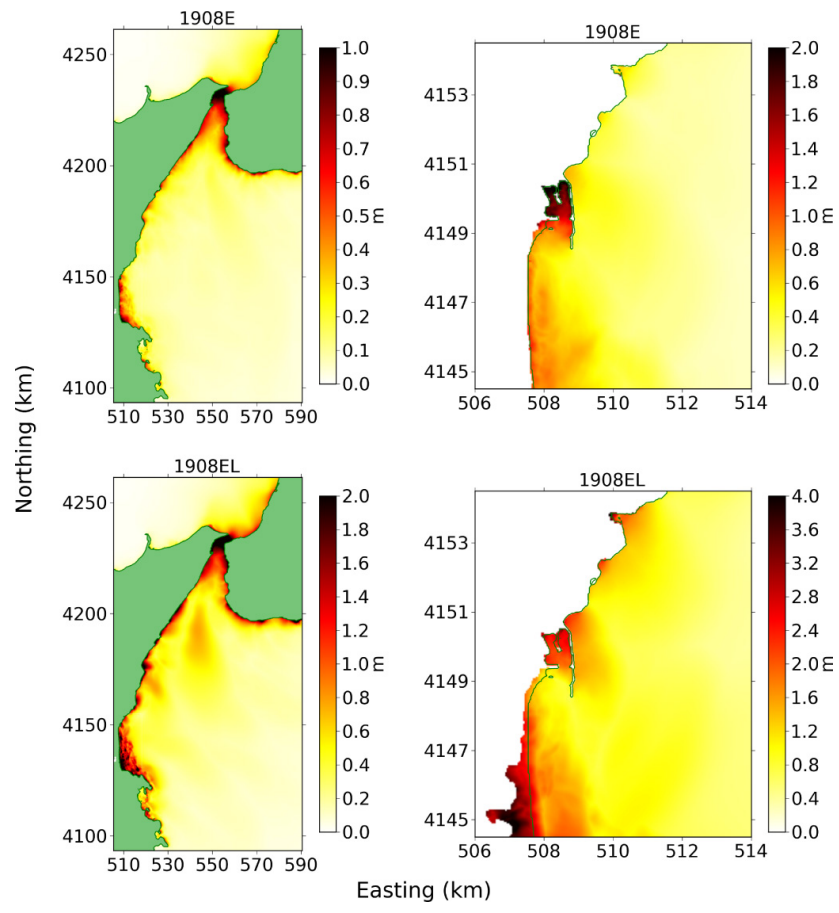

Fig. 11. Maximum water elevation for $1908 \mathrm{E}$ and $1908 \mathrm{EL}$ scenarios (left column) and their corresponding detailed maximum inundation in Catania (right column).

1983; Gerardi et al., 2008). The strong initial depression in the Messina Straits propagates as a negative leading wave towards south and after $9 \mathrm{~min}$ from the shock the front reaches the area offshore Catania (Fig. 10, upper panels). The maximum sea surface elevations are concentrated in the Messina Straits but some relevant local effects can also be found in the bay of Catania, especially in the south (see Fig. 11). Inside the harbour it is possible to note heights over $2 \mathrm{~m}$. The most inundated area is the west side of the outer harbour where the tsunami penetrates for some tens of meters inland (Fig. 11).

Very different results are obtained for the 1908 EL case, where the contribution of an equivalent landslide has been added to the earthquake source model $1908 \mathrm{E}$. The additional source is a static depression effective in producing a negative first front as suggested by the observations (Tinti and Giuliani, 1983). This additional source is not a landslide, strictly speaking, but instead a static depression of the sea surface. This choice is justified by the fact that sea floor mapping was not sufficient so far to identify a reasonable landslide body, and therefore assuming a specific landslide as a source could have been taken as quite arbitrary, or at least, as arbitrary as assuming the static depression. For this reason, to develop this scenario, there was no need to use codes specific to landslide dynamics computations (such as the one used for the scenario $1693 \mathrm{~L}$ ), and only a tsunami modelling code was utilised. A very strong leading negative front hits most of 

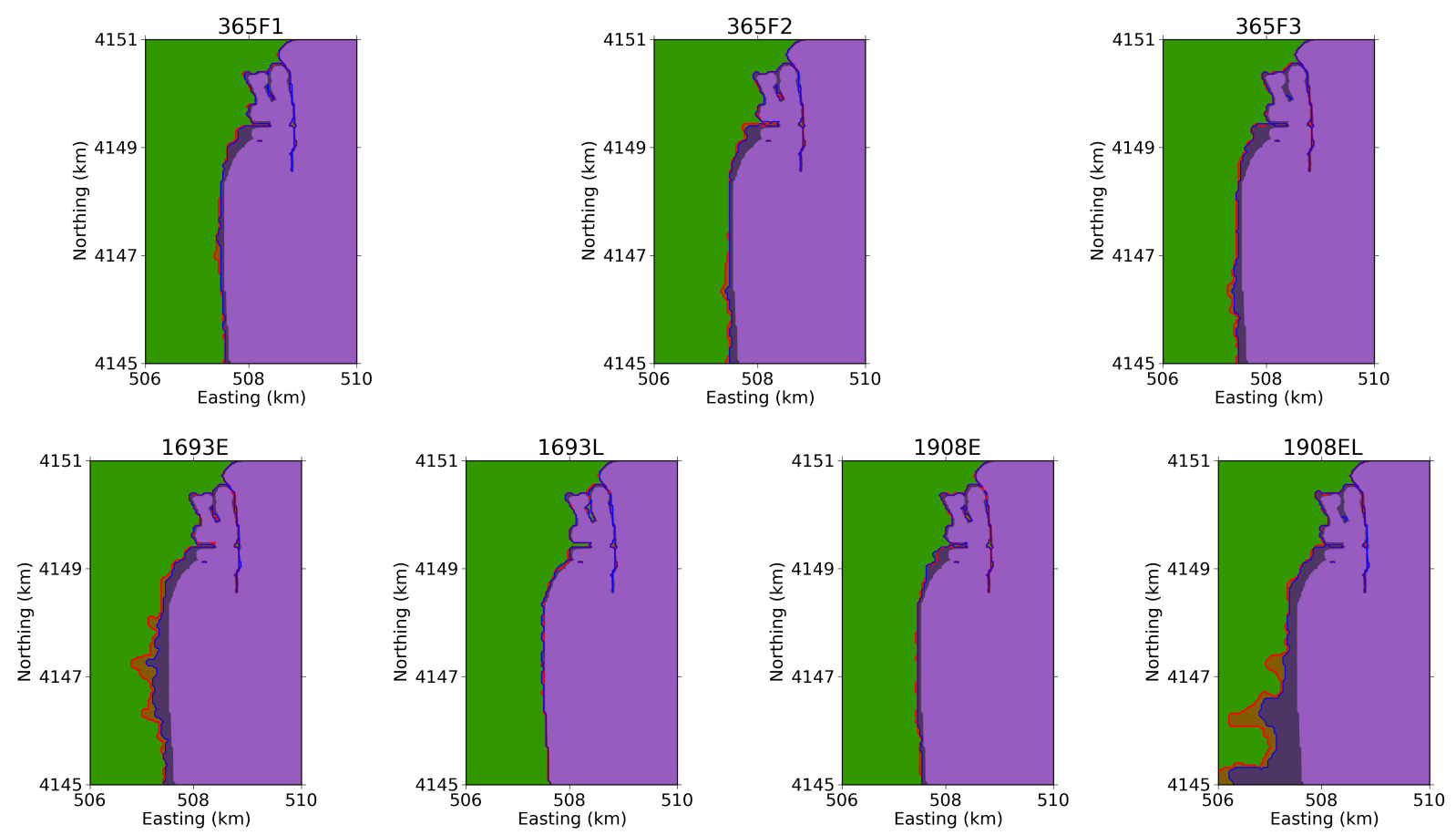

Fig. 12. Maximum inundation lines obtained for each one of the seven scenarios analysed: the blue ones are the inundation lines corresponding to the standard cases, while the inundation obtained by the augmented scenarios are delimited in red.

the coasts of eastern Sicily and south-western Calabria in a few minutes and after $9 \mathrm{~min}$ it faces the bay of Catania with higher elevation than the $1908 \mathrm{E}$ case (Fig. 10, bottom panels). The maximum sea surface elevation field displayed in Fig. 11 does not show a well defined pattern of energy propagation. It seems however that in the Straits and near the coasts the sea level increases remarkably with respect to offshore. The tsunami determines a strong inundation all along the coasts from the Catania harbour to the end of La Plaia, the latter experiencing the most pronounced flooding. The water penetrates about $1 \mathrm{~km}$ inland, with maximum elevation values between 4 and $5 \mathrm{~m}$ above the main sea level (Fig. 11).

\section{Uncertainties and sensitivity analysis}

The WCTSA approach relies on the definition of scenarios that should be credible, which means that sources (earthquake and landslides) should be compatible with the presentday seismo-tectonic and geomorphologic knowledge of the region, and that source sizes should be consistent with historical data, i.e. they should not be smaller than known past sources. Uncertainties are however unavoidable, since they often stem from poor scientific knowledge of the region, which implies a certain degree of arbitrariness in the process of scenario selection by researchers who make use of their subjective expertise. In the present study, large uncertainties are found in the knowledge of the sources of the 1693 and
1908 tsunamis with discussion still well alive among scientists and no conclusive point yet made. This kind of uncertainty has been addressed by making recourse to a double scenario for each event including earthquake (1693 $\mathrm{E}$ and $1908 \mathrm{E})$ and landslide (1693 L) or landslide-type (1908 EL) sources.

A further gender of uncertainty is related to the size of the source. In case of an earthquake source, for example, the worst case scenario requires one to assess the maximum magnitude to associate with a given fault. After assuming that this magnitude cannot be smaller than the largest magnitude recorded in the seismic catalogue for that fault, the assessment remains a quite difficult task and uncertainties of about $0.2-0.3$ or even larger are to be expected. The largest magnitude we have taken for the earthquake of the $365 \mathrm{AD}$ scenario is $M_{\mathrm{W}}=8.5$, but quite well it could be even 8.3 or 8.7. The same argument can be used for the other earthquake sources (1693 E and $1908 \mathrm{E}$ ) and for the size of the landslide sources (1693 L and $1908 \mathrm{EL}$ ). Treating uncertainties means to adopt an operational strategy to obtain results even in the presence of uncertain premises. The strategy adopted in this study is to take the scenarios elaborated with the sources illustrated so far as reference or standard worst-case scenarios, and to complement them with a sensitivity analysis consisting of computing as many scenarios obtained by incrementing the source size by a given amount, in the present case by $20 \%$. More specifically, when the tsunami source is an earthquake, then the initial tsunami sea surface displacement 

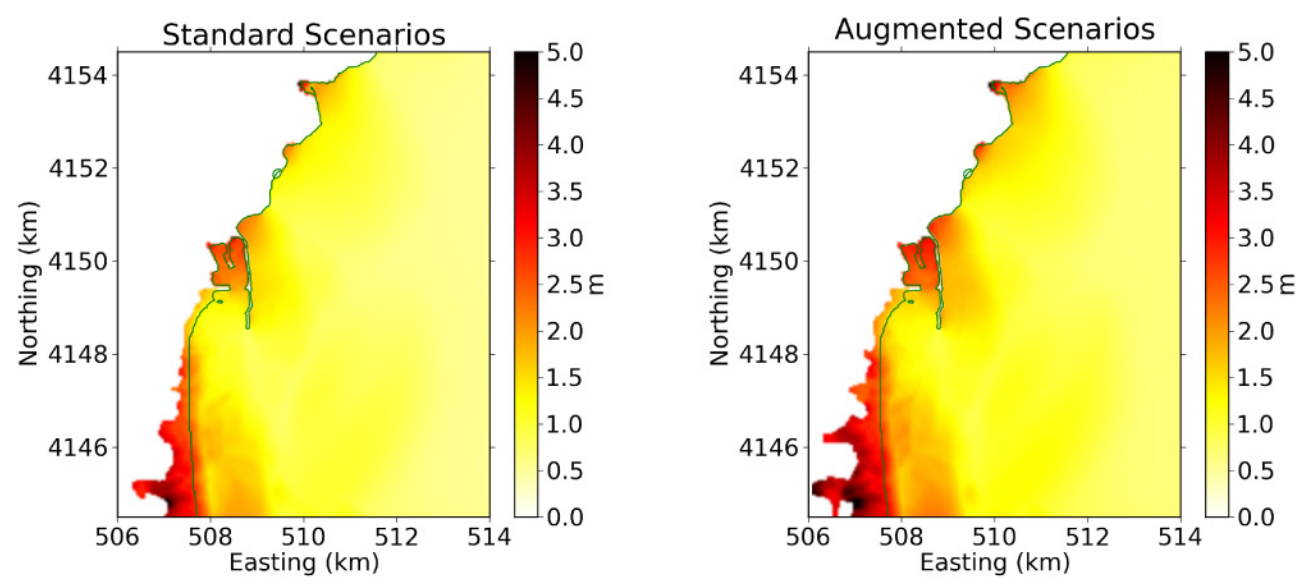

Fig. 13. Maximum water elevation for both the aggregate standard (left) and augmented (right) scenario.

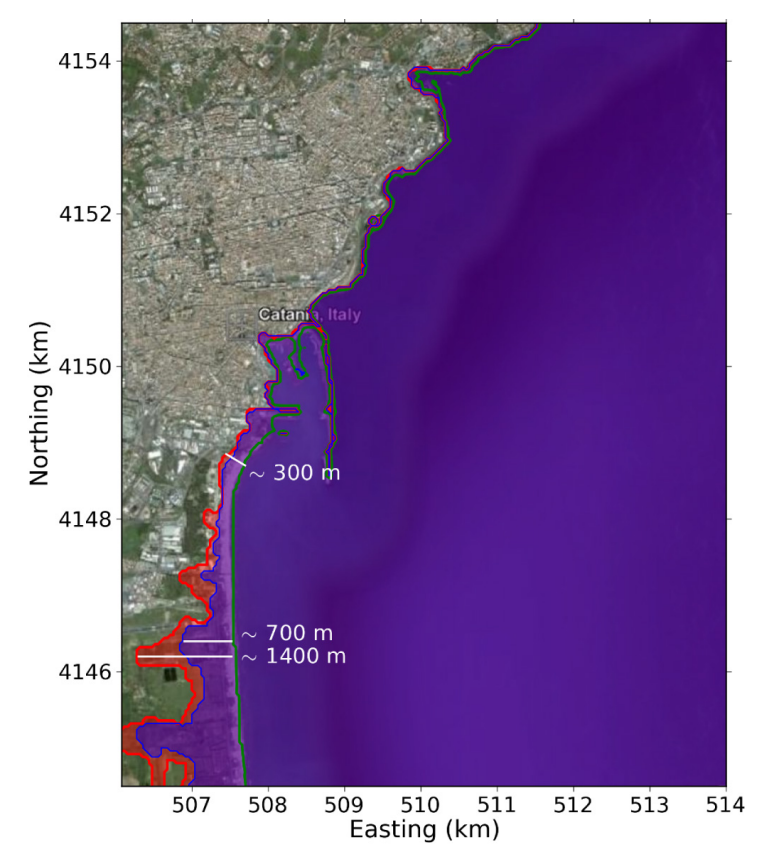

Fig. 14. Maximum inundation lines obtained for the aggregate standard scenario (blue line) and for the aggregate augmented scenario (red line).

is increased by $20 \%$, which corresponds theoretically to an increment of an equal amount of the co-seismic slip in the fault plane. When the tsunami source is a landslide, then the quantities incremented by $20 \%$ are the tsunami impulses imparted by the moving submarine landslide to the water, which roughly corresponds to an increment of the slide thickness by the same amount. These new scenarios are called augmented scenarios and expectedly produce larger tsunamis and larger inundations.

The motivation of the sensitivity analysis strategy chosen here is that, differently to the PTHA approach that plays with all source parameters of a reference scenario, the objective of the WCTSA is to use the minimum number of simulations needed to show how the inundation at the coast is sensitive to the characteristics of the tsunami, the main focus therefore being on the target area and not on the source. The main question is: how will the inundation change in case of a slightly larger tsunami? The best and simplest way to get such a tsunami in the target area is to slightly increase the on-fault slip value and therefore the magnitude of the tsunamigenic earthquake or the thickness of the tsunamigenic slide. What interests most is that by slightly changing (about 20\%) the height of the incoming tsunami, one might observe coastal zones where this change has practically no effects and other zones where the extent of flooding changes significantly. If results obtained from standard and augmented scenarios are quite similar, one can infer that there is some insensitivity to the source size. On the contrary, if they are quite different, hypotheses on the source magnitude are proven to be crucial, and efforts should be made to find more stringent constraints.

\section{Hazard maps}

Single scenarios associated with a given source can be described and illustrated by means of hazard maps providing fields of relevant hydrodynamic variables such as the maximum and minimum sea water elevations, maximum currents and maximum flow depths, etc.; and the problem to define a standard matrix of variables to plot, that is to define canonical types of hazard maps, has become an important issue for international bodies involved in the implementation of tsunami early warning systems and of strategies to mitigate tsunami risk (e.g. the Intergovernmental Coordination Groups ICG - of the IOC active in the Pacific, Indian Ocean, the Mediterranean and the Caribbean seas) and has been addressed by international tsunami projects like TRANSFER. 

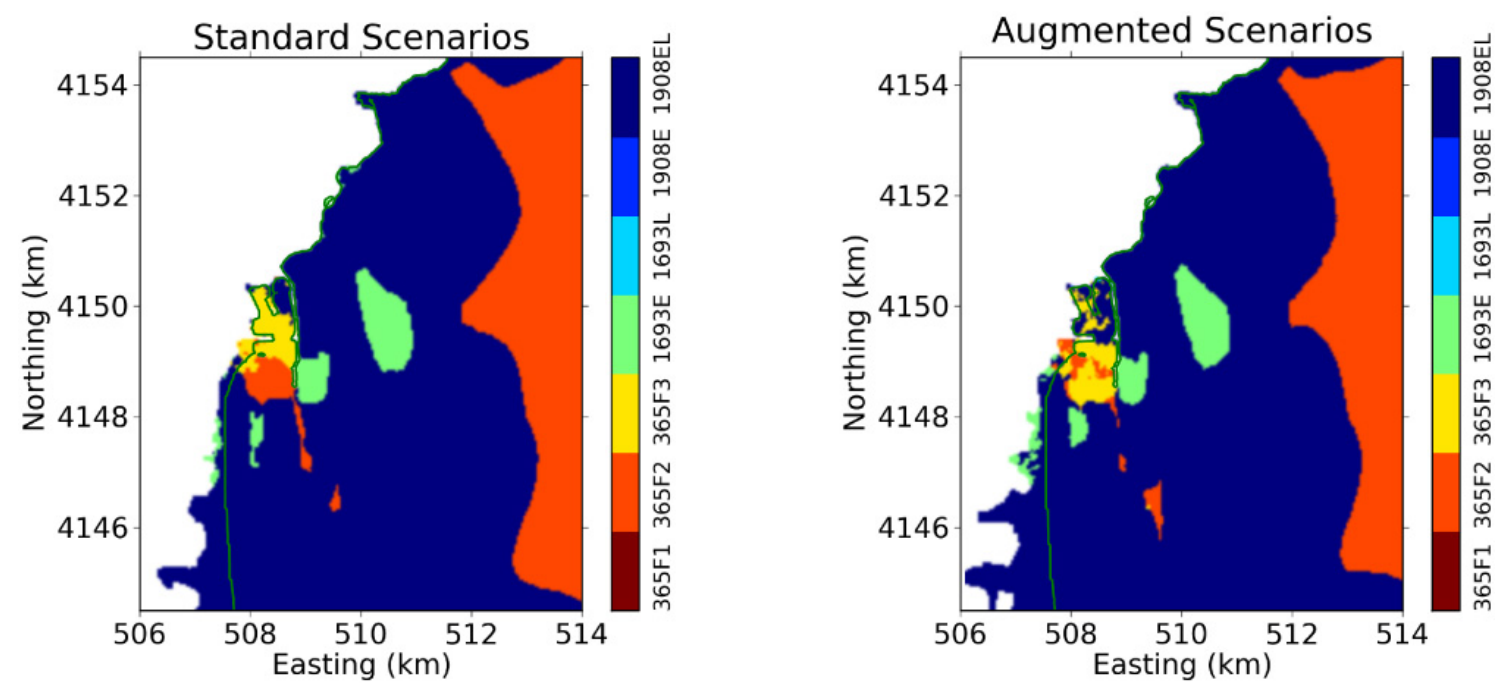

Fig. 15. Contribution of each scenario to the worst aggregate scenario for the standard cases (left) and for the augmented ones (right).

Among the possible hazard maps the most interesting are maps portraying the maximum elevation heights above the sea level that are illustrated in Fig. 12, since they convey the clearest information about the extension of the tsunami inundation. Important elements in these maps are the maximum inundation lines. For each scenario the maximum inundation line is defined as the curve that embraces all the areas on land that result to be flooded temporarily or permanently by the tsunami. In this set of maps, one can see the maximum inundation lines of the standard scenarios (blue) plotted together with the corresponding lines of the augmented scenarios (red). Comparison of results of standard vs. augmented scenarios is a relevant issue and deserves further comments. All the numerical simulations with the code UBO-TSUFD have been performed by solving linear equations in the domain covered by grids 1 and 2 and non-linear equations in grids 3 and 4, the last one embracing the target area of Catania. This leads to the trivial consequence that by incrementing the source magnitude by a certain amount does not correspond to an increasing of the resulting fields (sea elevation and velocity) by the same amount. Non-linear terms of the equations affect the inundation results quite unequally as is illustrated in Fig. 12, where inundation areas of standard and augmented scenarios are compared by means of the maximum inundation lines. Differences between standard and augmented sources are small for scenarios $365 \mathrm{~F} 1$, $365 \mathrm{~F} 2$ and $365 \mathrm{~F} 3$ and almost unrecognizable for scenario $1693 \mathrm{~L}$ and $1908 \mathrm{E}$. These two last scenarios are quite weak and increasing the tsunami source does not affect the final inundation that remains modest. Instead, important differences can be found for scenarios $1693 \mathrm{E}$ and $1908 \mathrm{EL}$ that give the largest inundations at La Plaia beach even for the standard sources: the inundated areas of their corresponding augmented scenarios are significantly larger than the stan- dard ones in some specific areas. This is caused by the morphology of the coast, which is very low in La Plaia with some mild undulations or dunes, so that once the tsunami surpasses a certain threshold, the sea flow inundates all the area behind the dunes.

\section{Aggregated scenarios}

The last step of the WCTSA method is to obtain a unique picture from the scenarios corresponding to the selected tsunami sources. To this purpose, all scenarios are combined together into an aggregate scenario that provides the worst of worstcase scenarios for any place of the target area, namely, in view of the numerical discretisation, in each node of the subgrid 4 within the red rectangle displayed in Fig. 5. Selecting the worst (largest) of worst-case values corresponds perfectly well to the spirit of the WCTSA approach. It is worth observing that the resulting fields are virtual fields that cannot be associated with any specific scenario, but that provide the highest level of hazard that is expected in each part of the map. The maps have been computed for the aggregate standard scenario and for the aggregate augmented scenarios. From Fig. 13 it is seen that a large part of the La Plaia beach is deeply flooded and also that the area around the harbour is flooded, especially in correspondence with the outer basin. In the northern part, the only remarkable effects can be found in the small harbour of Ognina, where waves about 3-4 $\mathrm{m}$ high attack the bay. In Fig. 14 the maximum inundation line is plotted for both standard and augmented aggregate scenarios. The flooded areas are limited by blue and red lines for the standard and augmented sources respectively, and the differences between them in terms of maximum inundation extension are clearly visible. At La Plaia beach the extent of the inundation for both standard (maximum about 
$1400 \mathrm{~m}$ ) and augmented (maximum over $1600 \mathrm{~m}$ ) aggregated scenarios exceeds hundreds of metres in many places and reaches about $300 \mathrm{~m}$ at the entry of the harbour. In Fig. 15 the contribution given by each single scenario to the aggregated map is shown. It is evident that the scenario contributing most is the $1908 \mathrm{EL}$, but also scenarios $365 \mathrm{~F} 2,365 \mathrm{~F} 3$, and $1693 \mathrm{E}$, though of minor relevance in extension, give important results as could already be inferred by observing the inundation maps of each scenario (Fig. 13). The important new information here is how the contribution is distributed geographically: the 1908 EL scenario is the one which triggers the highest waves and its contribution is higher on the flat beach of La Plaia, whereas the 365 F2 and 365 F3 scenarios are the main contributor inside the harbour, because in these cases tsunami wavelength probably triggers stationary oscillations that are characteristic of the harbour basin. A further important contribution is given by $1693 \mathrm{E}$ in a small area immediately to the south of the harbour entrance.

\section{Conclusions}

A WCTSA aiming at the evaluation of tsunami hazard for the city of Catania, eastern Sicily, Italy, has been performed. Seven sources have been selected as strongly potentially tsunamigenic in order to simulate the worst-case tsunami scenarios that could affect Catania, and a sensitivity study on these tsunami sources has also been undertaken. All the results have been obtained by means of numerical modelling. The tsunami hazard analysis has been completed by the use of aggregate maps that provided the worst of the worst-case scenarios expected in each point of the target area. From the simulations it results that the areas most exposed to potential flooding are the beach called La Plaia, the southernmost part of the harbour and the small jetties inside the harbour. From the aggregate maps it has been possible to distinguish the contribution of each single scenario to the global hazard. The two chief contributing scenarios turn out to be the 365 F2, 365 F3 cases and the 1908 EL case. The latter is a hypothetical case based on the combination of the actual seismological and tectonic studies of the 1908 event and an empirical source argued on the basis of tsunami observations. The former are based on the partial or complete rupture of the western HA, including the portion that possibly triggered the 365 AD tsunami: these are remote sources that produce the highest sea elevation values in the harbour area and in the part of La Plaia beach that is closest to the harbour. This is relevant, since it shows that remote sources have an important role in tsunami hazard assessment for the site of Catania, and also has a significant implication for tsunami early warning system implementation. Sensitivity analysis has shown that the same scenarios that happen to be the most important for tsunami hazard are also the ones more sensible to the size of the tsunami sources. This poses the question of undertaking research in the near future to improve our knowledge of the tsunami sources and, since it emerges that local and remote sources are relevant for the town of Catania, it results that studies aiming at a better characterisation of the tsunamigenic sources in the Calabrian Arc and in the Hyblean-Malta escarpment, including the stability of the Ionian margin, and of the seismic potential of the western HA will be of great advantage to the town.

Acknowledgements. The work has been developed in the framework of the EU-funded project SCHEMA, where Catania has been chosen as one of the test sites on which carrying out tsunami vulnerability and risk studies. Bathymetric and topographic data have been collected with the cooperation of the Civil Protection Office (regional Department and Provincial section) of the Regione Sicilia. Satellite image used in Fig. 14 is taken from Google Earth (C) 2010 Google). The full credit is: Image (C) 2010 DigitalGlobe, Data SIO, NOAA, US Navy, NGA, GEBCO, Image (C) 2010 GeoEye, (C) 2010 Tele Atlas.

Edited by: I. Didenkulova

Reviewed by: two anonymous referees

\section{References}

Annaka, T., Satake, K., Sakakiyama, T., Yanagisawa, K., and Shuto, N.: Logic-tree approach for probabilistic tsunami hazard analysis and its applications to the Japanese coasts, Pure Appl. Geophys., 164, 577-592, 2007.

APAT: Atlante delle onde dei mari italiani. Dipartimento Tutela Acque Interne e Marine, Servizio Mareografico, 152 pp., Roma, 2006 (in Italian).

Argnani, A. and Bonazzi, C.: Malta Escarpment fault zone offshore eastern Sicily: Pliocene-Quaternary tectonic evolution based on new multichannel seismic data, Tectonics, 24, TC4009, doi:10.1029/2004TC001656, 2005.

Argnani, A., Chiocci, F. L., Tinti, S., Bosman, A., Lodi, M. V., Pagnoni, G., and Zaniboni, F.: Comment on "On the cause of the 1908 Messina tsunami, southern Italy" by Andrea Billi et al., Geophys. Res. Lett., 36, L13307, doi:10.1029/2009GL037332, 2009.

Armigliato, A., Tinti, S., Argnani, A., Zaniboni, F., and Pagnoni, G.: Tsunamigenic potential of recently mapped submarine mass movements offshore eastern Sicily (Italy): numerical simulations and implications for the 1693 tsunami, IUGG XXIV General Assembly, Perugia (Italy), 2-13 July 2007, Abstract JSS002-1811, 2007.

Baratta, M.: I terremoti d'Italia. Saggio di storia, geografia e bibliografia sismica italiana (ristampa anastatica, Sala Bolognese 1979), 1901.

Baratta, M.: La catastrofe sismica calabro-messinese (28 dicembre 1908), Relazione alla Società Geografica Italiana, Roma: Società Geografica Italiana, 1910.

Bianca, M., Monaco, C., Tortorici, L., and Cernobori, L.: Quaternary normal faulting in southeastern Sicily (Italy): A seismic source for the 1693 large earthquake, Geophys. J. Int., 139, 370394, 1999.

Billi, A., Funiciello, R., Minelli, L., Faccenna, C., Neri, G., Orecchio, B., and Presti, D.: On the cause of the 1908 Messina 
tsunami, southern Italy, Geophys. Res. Lett., 35, L06301, doi:10.1029/2008GL033251, 2008.

Blaser, L., Krüger, F., Ohrnberger, M., and Scherbaum, F.: Scaling Relations of Earthquake Source Parameter Estimates with Special Focus on Subduction Environment, Bull. Seism. Soc. Am., 100(6), 2914-2926, doi:10.1785/0120100111, 2010.

CPTI Working Group: Catalogo Parametrico dei Terremoti Italiani, versione 2004 (CPTI04), INGV, Bologna, 2004.

Favalli, M., Boschi, E., Mazzarini, F., and Pareschi, M. T.: Seismic and landslide source of the 1908 Straits of Messina tsunami (Sicily, Italy), Geophys. Res. Lett., 36, L16304, doi:10.1029/2009GL039135, 2009.

Geist E. and Parsons T.: Probabilistic analysis of tsunami hazards, Nat. Hazards, 37, 277-314, 2006.

Gerardi, F., Barbano, M. S., De Martini, P. M., and Pantosti, D.: Discrimination of tsunami sources (earthquake vs. landslide) on the basis of historical data in eastern Sicily and southern Calabria, Bull. Seism. Soc. Am., 98(6), 2795-2805, 2008.

Grezio, A., Marzocchi, W., Sandri, L., and Gasparini, P.: A Bayesian procedure for Probabilistic Tsunami Hazard Assessment, Natural Hazards, 53(1), 159-174, doi:10.1007/s11069009-9418-8, 2010.

Guidoboni, E. and Comastri, A.: Catalogue of Earthquakes and Tsunamis in the Mediterranean Area from the 11th to the 15th Century, Istituto Nazionale di Geofisica e Vulcanologia - Storia Geofisica Ambiente (INGV-SGA), Italy, 2005.

Gutscher, M.-A., Roger, J., Baptista, M.-A., Miranda, J. M., and Tinti, S.: Source of the 1693 Catania earthquake and tsunami (southern Italy): New evidence from tsunami modeling of a locked subduction fault plane, Geophys. Res. Lett., 33, L08309, doi:10.1029/2005GL025442, 2006.

Hanks, T. C. and Kanamori, H.: A moment magnitude scale, J. Geophys. Res., 84(B5), 2348-2350, 1979.

Loperfido, A.: Livellazione geometrica di precisione eseguita dall'I.G.M. sulla costa orientale della Sicilia, da Messina a Catania, a Gesso ed a Faro Peloro e sulla costa occidentale della Calabria da Gioia Tauro a Melito di Porto Salvo. In Relazione della Commissione Reale incaricata di designare le zone più adatte per la ricostruzione degli abitati colpiti dal terremoto del 28 dicembre 1908 o da altri precedenti, Roma: Accademia Nazionale dei Lincei, 131-156, 1909.

Lorito, S., Tiberti, M. M., Basili, R., Piatanesi, A., and Valensise, G.: Earthquake-generated tsunamis in the Mediterranean Sea: Scenarios of potential threats to Southern Italy, J. Geophys. Res., 113, B01301, doi:10.1029/2007JB004943, 2008.

Monaco, C. and Tortorici, L.: Active faulting in the Calabrian arc and eastern Sicily, J. Geodyn., 29, 407-424, 2000.

Okada, Y.: Internal deformation due to shear and tensile faults in a half-space, Bull. Seism. Soc. Am., 82, 1018-1040, 1992.

Okal, E. A. and Synolakis, C. E.: Far-field tsunami hazard from mega-thrust earthquakes in the Indian Ocean, Geophys. J. Int., 172, 995-1015, doi:10.1111/j.1365-246X.2007.03674.x, 2008.

Papaioannou, Ch. A., Papazachos, C. B., and Scordilis, E. M.: A catalogue of earthquakes in Greece and surrounding area for the period 550BC-1999, Publ. Geophys. Laboratory, University of Thessaloniki, 1, 333 pp., 2000.

Papazachos, B. C.: Large Seismic Faults in the Hellenic Arc, Annali di Geofisica, 39, 891-903, 1996.

Papazachos, B. C., Comninakis, P. E., Scordilis, E. M., Karakaisis,
G. F., and Papazachos, C. B.: A catalogue of earthquakes in the Mediterranean and surrounding area for the period 1901-2007, Publ. Geophys. Laboratory, University of Thessaloniki, avaliable online at: http://www.geo.auth.gr/courses/database/seismology/ 550bc-2007.pdf, 2007.

Pino, N. A., Piatanesi, A., Valensise, G., and Boschi, E.: The 28 December 1908 Messina Straits Earthquake $\left(M_{\mathrm{W}} 7.1\right)$ : A Great Earthquake throughout a Century of Seismology, Seism. Res. Lett., 80, 2, 243-259, 2009.

Platania, G.: Il maremoto dello Stretto di Messina del 28 dicembre 1908, Boll. Soc. Sism. Ital., 13, 369-458, 1909a.

Platania, G.: I fenomeni marittimi che accompagnarono il terremoto di Messina del 28 dicembre 1908, Riv. Geogr. Ital., 16, 154-161, $1909 b$.

Power, W., Downes, G., and Stirling, M.: Estimation of Tsunami Hazard in New Zealand due to South American Earthquakes, Pure Appl. Geophys., 164, 547-564, 2007.

Shaw, B., Ambraseys, N. N., England, P. C., Floyd, M. A., Gorman, G. J., Higham, T. F. G., Jackson, J. A., Nocquet, J.-M., Pain, C. C., and Piggott, M. D.: Eastern Mediterranean tectonics and tsunami hazard inferred from the AD 365 earthquake, Nat. Geosci., 1, 268-276, doi:10.1038/ngeo151, 2008.

Sirovich, L. and Pettenati, F.: Seismotectonic outline of SouthEastern Sicily: An evaluation of available options for the earthquake fault rupture scenario, J. Seismol., 3, 213-233, 1999.

Stiros, S. C.: The AD 365 Crete Earthquake and Possible Seismic Clustering during the Fourth to Sixth Centuries AD in the Eastern Mediterranean: A Review of Historical and Archaeological Data, J. Struct. Geol., 23, 545-562, 2001.

Strasser, F. O., Arango, M. C., and Bommer, J. J.: Scaling of the source dimensions of interface and intraslab subduction-zone earthquakes with moment magnitude, Seismol. Res. Lett., 81(6), 941-950, doi:10.1785/gssrl.81.6.941, 2010.

Tinti, S. and Giuliani, D.: The Messina Straits tsunami of December 28, 1908: A critical review of experimental data and observations, Il Nuovo Cimento, 6, 429-442, 1983.

Tinti, S. and Maramai, A.: Catalogue of tsunamis generated in Italy and in Côte d'Azur, France: a step towards a unified catalogue of tsunamis in Europe, Ann. Geof., 39, 1253-1299, 1996.

Tinti, S. and Armigliato, A.: The use of scenarios to evaluate the tsunami impact in southern Italy, Mar. Geol., 199, 221-243, 2003.

Tinti, S., Bortolucci, E., and Vannini, C.: A block-based theoretical model suited to gravitational sliding, Nat. Hazards, 16, 1-28, 1997.

Tinti, S., Maramai, A., and Graziani, L.: A new version of the European tsunami catalogue: updating and revision, Nat. Hazards Earth Syst. Sci., 1, 255-262, 2001a, http://www.nat-hazards-earth-syst-sci.net/1/255/2001/.

Tinti, S., Armigliato, A., and Bortolucci, E.: Contribution of tsunami data analysis to constrain the seismic source: The case of the 1693 eastern Sicily earthquake, J. Seismol., 5, 41-61, 2001b.

Tinti, S., Maramai, A., and Graziani, L.: The new catalogue of the Italian tsunamis, Nat. Hazards, 33, 439-465, 2004.

Tinti, S., Armigliato, A., Pagnoni, G., and Zaniboni, F.: Scenarios of giant tsunamis of tectonic origin in the Mediterranean, ISET J. Earthq. Techn., 42, 171-188, 2005a.

Tinti, S., Armigliato, A., Tonini, R., Maramai, A., and Graziani, L.: Assessing the Hazard related to tsunamis of tectonic origin,: A 
hybrid statistical-deterministic method applied to southern Italy coasts, ISET, J. Earthq. Techn., 42, 189-201, 2005b.

Tinti, S., Pagnoni, G., and Zaniboni, F.: The landslides and tsunamis of the 30th of December 2002 in Stromboli analysed through numerical simulations, Bull. Volcanol., 68, 462-479, doi:10.1007/s00445-005-0022-9, 2006.

Titov, V. V., González, F. I., Bernard, E. N., Eble, M. C., Mofjeld, H. O., Newman, J. C., and Venturato, A. J.: Real-time tsunami forecasting: Challenges and solutions, Nat. Hazards, 35(1), Special Issue: US National Tsunami Hazard Mitigation Program, 41-58, 2005.

Tonini, R., Armigliato, A., and Tinti, S.: The 29th September 2009 Samoa Islands tsunami: Preliminary simulations based on the first focal mechanisms hypotheses and implications on tsunami early warning strategies, Pure and Applied Geophysics (ITS Special Issue), doi:10.1007/s00024-010-0221-y, published online 11 January 2011, 2011.
Valensise, G., Basili, R., and Burrato, P.: La sorgente del terremoto del 1908 nel quadro sismotettonico dello Stretto di Messina, in "Il terremoto e il maremoto del 28 dicembre 1908: analisi sismologica, impatto, prospettive", edited by: Bertolaso, G., Boschi, E., Guidoboni, E., and Valensise, G., 161-182, 2008.

Wells, D. L. and Coppersmith, K. J.: New Empirical Relationships among Magnitude, Rupture Length, Rupture Width, Rupture Area, and Surface Displacement, Bull. Seism. Soc. Am., 84, 974-1002, 1994. 